\title{
O Método Comparativo na Origem da Psicologia da ARTE ${ }^{1}$
}

\author{
Arley Andriolo ${ }^{2}$ \\ Instituto de Psicologia - USP
}

Este textotemporobjetivo apresentaro surgimento do método comparativo nas interpretações psicológicas das produções artísticas da Europa e do Brasil. Utilizam-se os discursos da Psiquiatria no início do século XX, notando como as interpretações básicas acerca da Psicologia da Arte foram permeadas pelo método comparativo. Este, por sua vez, carregou consigo um risco de análise, o de encontrar na arte uma manifestação de degeneração.

Descritores: Arte (Psicologia). Alteridade. Arte degenerada.

\section{Introdução}

localização de um método de abordagem comparativa de obras plásti-
esas, em escritos do início do século XX, nos instigou a pensar: quando
esse procedimento apareceu na Psicologia da Arte e quais os problemas que
evidencia, sobretudo, no contexto da cultura brasileira? Assim, nosso objetivo
será mostrar a aparição desse método, designado genericamente "comparati-
vo", na origem da Psicologia da Arte, cumprindo uma função bastante espe-

1 Este texto é oriundo da tese de doutorado do autor intitulada "Traços primitivos: histórias do outro lado da arte no século XX”, defendida em 2004, no Instituto de Psicologia da Universidade de São Paulo. Contou com o apoio da FAPESP.

2 Docente do Departamento de Psicologia Social e do Trabalho, Laboratório de Estudos em Psicologia da Arte do Instituto de Psicologia - USP. Endereço para correspondência: Av. Prof. Mello Moraes, 1721, Bloco A, Cidade Universitária, São Paulo, SP. CEP 05508-030. Endereço eletrônico: arley@usp.br 
cífica na comparação de obras produzidas por grupos sociais muito distintos, curiosamente por intermédio do discurso psicopatológico.

Como observou Frayze-Pereira (1994, p. 37), o surgimento de uma "psico-estética experimental", através dos estudos de Wundt, cujo laboratório em Leipzig data de 1878, ocorre na mesma época em que G. T. Fechner propõe o termo "estética indutiva", em sua Introdução à Estética (1876). Desde então, a Universidade de Viena ocupou um lugar importante no encontro da Psicologia com as teorias da arte (por exemplo, Wickhoff, Riegl, Strzygowski). Além da teoria gestáltica, surgida por volta de 1890, em Viena, desenvolveu-se o grupo formador do Instituto Warburg (depois transferido para Londres), do qual fizeram parte, entre outros, E. Gombrich e E. Panofsky. Rudolf Arnheim, saído de Berlim, ocupará a primeira cátedra de Psicologia da Arte no Sarah Lawrence College de Bronxville (Nova Iorque, 1943), enquanto René Huyghe assumiu a segunda no Collège de France (Paris, 1951) (Glusberg, 1991, p. 60).

Naquela virada de século, o campo da Psiquiatria ocupou um lugar importante na mediação entre os estudos de Psicologia e os estéticos, fornecendo material abundante de casos clínicos. Em vários modelos de interpretação - "psicopatologia da arte", "Gestaltung artística", "psicanálise da arte" etc. -, é possível notar a participação do método comparativo. Como veremos, o procedimento de traçar paralelos entre obras produzidas por crianças, loucos e povos aborígines permeou tacitamente as pesquisas, deixando implícito um problema apenas evidenciado durante a Segunda Guerra Mundial. ${ }^{3}$

\section{A obra dos asilos e o método comparativo}

O surgimento do discurso que relacionou Arte e Psicopatologia pode ser localizado na segunda metade do século XIX, como parte de um fenômeno histórico relativo ao positivismo científico, à teoria evolucionista e, de maneira mais ampla, ao imperialismo europeu.

3 O período posterior à Segunda Guerra Mundial corresponde a uma revisão desse método, às vezes em continuidade, noutras em reelaborações críticas, algumas em completa recusa. Esse período será objeto de um estudo a ser publicado pelo autor. 
Em 1845, o alienista Pliny Earle, um dos fundadores da organização que se tornou a American Psychiatric Association, publicou um ensaio sobre a produção artística de "insanos". Pela primeira vez, observou-se o desenvolvimento teórico da Psiquiatria no sentido da Estética. Três anos depois, o alienista britânico Forbes Winslow continua esse interesse no artigo "On the insanity of men of genius" (Journal of Psychological Medicine, n. 2, 1848, pp. 262-291), por meio do qual observou as semelhanças entre pinturas realizadas por doentes mentais, coletadas em vários asilos britânicos por mais de vinte anos (Gilman, 1995, p. 221).

Na França, o psiquiatra francês Abroise Tardieu (1872), em seu Études medico-légale sur la folie, atraía a atenção para a pintura de doentes mentais, quando escrevia que: "não temo dizer que se encontrará muitas vezes um interesse real em examinar os desenhos e as pinturas produzidas pelos loucos" (citado por Volmat, 1955, p. 29) ${ }^{4}$. Quatro anos depois, um artigo assinado por Max Simon, médico junto ao asilo de Blois e chefe do serviço asilar de Bron, ganhou destaque como um dos pioneiros nesse domínio. Seu texto "L'imagination dans la folie: étude sur les dessins, plans, descriptions et costumes des aliénés" foi publicado nos Annales Médico-psychologiques (1876, pp. 358390). Simon elaborou correspondências entre as formas artísticas e seis categorias psiquiátricas do final do século XIX: "melancolia", "mania crônica", "megalomania", "paralisia geral do louco", "demência" e "imbecilidade".

Nessa primeira visada médica sobre a obra de "doentes mentais", a proposição preponderante dizia respeito à obra como um registro sintomático. A partir desses autores, manifestações artísticas de internos de hospitais psiquiátricos elevam-se à condição de documento clínico, possibilitando ao médico competente, por meio delas, delimitar o tipo de delírio e diagnosticar seus pacientes. Conforme observou Françoise Will-Levaillant (1980), uma constatação primordial se impõe: "todos os desenhos apresentados são estudados nos quadros do asilo, os doentes já estão lá como tais, ou seja, com o tipo de loucura que os designa” (p. 27, itálicos no original) ${ }^{5}$. Nesse contexto, os médicos viam uma espécie de "reflexo" entre doença e produção plástica, cabendo

4 “je ne crains pas de dire que l'on rencontrera souvent un intérêt réel à examiner les dessins et les peintures faites par les fous".

5 “tous les dessins présentés sont étudiés dans le cadre de l'asile, les malades sont déjà là comme tels, c'est-à-dire avec le type de folie qui les designe" 
ao discurso psicopatológico estabelecer as relações entre ambas.

Várias publicações do início do século XX seguiram essa orientação, não obstante suas variações. Para citar alguns exemplos da primeira década do século, começaríamos com Júlio Dantas editando uma monografia sobre as produções plásticas de doentes do Hospício de Rilhafolles (1900). August Marie, médico francês em Villejuif, por volta de 1905, abriu ao público um pequeno museu, expondo obras de seus pacientes; é o chamado Musée de la folie. Nesse mesmo ano, Rogues de Fursac escreveu Les écrits et les dessins dans maladies mentales et nerveuses (1905). Em língua alemã, é notável o trabalho do psiquiatra Fritz Mohr que publicou "Über zeichnungen von Geisteskranken und ihre diagnostische Verwertbarkeit" (publicou no Journal für Psychologie und Neurologie, n. 8, de 1906).

Dentre os instrumentos que compuseram o complexo aparato da percepção daquelas produções plásticas, aparece o método comparativo. As interpretações que consideravam as obras como indícios de patologia propunham a comparação com as criações de grupos humanos diversos, habitantes da África ou Oceania, considerados inferiores aos membros da cultura européia ocidental, sob um olhar etnocêntrico da virada do século. Nesse particular, é exemplar o caso de Cesar Lombroso. Conforme lembrou Osório Cesar, Lombroso reunira "produções artísticas" de 107 doentes mentais que começaram a pintar ou esculpir depois da moléstia: "Ele foi o primeiro observador que chamou a atenção para a semelhança da arte de alguns alienados com a arte primitiva e considerou as obras artísticas desses alienados como um retorno à infância da humanidade" (Cesar, 1955, p. 125).

A explicação da manifestação artística nos doentes mentais como expressão de mentalidade primitiva ou infantil, por intermédio do método comparativo, foi possível com o suporte da teoria da degenerescência, sobretudo com o próprio Lombroso, em Turim. A teoria da degeneração surgira em 1840, na França, tendo sido criada por B. A. Morel, estendendo-se em pouco tempo aos países europeus até cerca de 1913, quando foi contestada pela tese de G. Genil-Perrim. O gênio, para muitos intelectuais do século XIX, era uma neurose originária no mesmo terreno que a loucura. Magnan, por exemplo, dizia que esse era o domínio da degeneração, no qual o gênio seria um "degenerado superior" (Postel \& Quétel, 1987, pp. 353-356). 
Tal concepção conduziu à afirmação do alienado como alguém que retornou ao estado "primitivo" da civilização. Como se disse, essa idéia fundava-se numa ideologia evolutiva e imperialista própria do final do século XIX, considerando como não-civilizados os povos exteriores à cultura européia ocidental; grupos humanos que, naquele momento, estavam submetidos à dominação econômica e política das potências da Europa.

\section{Estética comparada da "arte dos alienados"}

No início do século XX, esse "olhar diagnóstico" deixa de ser único. ${ }^{6}$ Marcel Réja, por exemplo, entre 1901 e 1907, publicou dois textos acerca de "L'art malade: dessins de fous" (1901) e L'art chez les fous: le dessin, la prose, la poésie (1907). Assinando um pseudônimo (seu nome era Paul Meunier), esse médico dedicou-se à crítica de arte e à crítica literária, sendo considerado entre os estudiosos da visada médica sobre a Arte como o primeiro a notar elementos propriamente artísticos naquelas obras, ainda que estivessem presentes em suas análises traços da interpretação psicopatológica. Conforme Thévoz (1990, p. 92), Réja afasta-se das categorias clínicas da Psiquiatria para uma reflexão antropológica sobre a função simbólica, associando a arte das crianças, dos prisioneiros, dos espíritas, dos primitivos etc. Assim: "Réja contribuiu para lançar as bases de uma estética comparada e para abalar os dogmas da representação acadêmica" (p. 95). ${ }^{7}$

O ano de 1922 foi marcante na história das interpretações médicas sobre a "arte nos alienados" com a publicação do livro de Hans Prinzhorn. Esse intelectual cursou Filosofia e História da Arte, defendendo tese em 1908 na Universidade de Munique sobre o arquiteto Gottfried Semper (1803-1879). Em 1917, formou-se também em Psiquiatria, quando foi trabalhar junto de Karl Wilmanns, na clínica psiquiátrica universitária de Heidelberg (Weber, 1984, p. 5). Em dois anos e meio, organizou ali uma coleção de mais de cinco mil peças,

6 O principal exemplo dessa questão data de 1921, quando foi publicada a primeira monografia dedicada a um interno de hospital psiquiátrico, escrita pelo psiquiatra suíço Walter Morgenthaler, no livro intitulado Ein Geisteskranker als Künstler (1921), no qual se refere a "um artista alienado" chamado Adolf Wölfli.

7 "Réja a contribué à poser les bases d'une esthétique comparée et à ébranler les dogmes de la représentation académique". 
reunindo obras provenientes de vários asilos europeus, com as quais realizou o mais amplo estudo da produção artística de internos daquele momento.

Seu livro foi intitulado Bildnerei der geisteskranken, posteriormente traduzido para o inglês como Artistry of the mentally ill e para o francês como Expressions de la folie; Mário Pedrosa se referiu ao título como Imaginária dos doentes mentais. Tal designação procurava demonstrar o descontentamento do autor diante de nomenclaturas nos moldes de "arte dos loucos", "arte dos doentes mentais", ou "arte patológica” (Prinzhorn, 1922/1984, p. 53).

Do ponto de vista metodológico, Prinzhorn propôs uma fenomenologia de maneira ampla, sem relação direta com Husserl. Nos estudos posteriores ao livro de 1922, passa a valer-se de instrumentos teóricos oriundos da Psicanálise, no entanto, de modo distinto de muitos freudianos (por exemplo, Kris, 1968). Também o próprio autor lembra que estava consciente das simplificações apresentadas para sua formulação de Gestaltung, procurando, naquele momento, evitar o debate com as pesquisas psicológicas de Witasek, Koffka, Wertheimer, Khöler, entre outros. Sua utilização do conceito de Gestaltung artística ao longo da obra tem como objetivo encontrar, do ponto de vista cultural e estético, um núcleo criador comum a todos os homens (Prinzhorn, 1922/1984, p. 50).

O procedimento de comparação, encontrado em 1922, fora aplicado por Prinzhorn um ano antes, num artigo dedicado aos desenhos de doentes mentais e de "primitivos", intitulado "Uber Zeichnungen Geisteskranker und Primitiver" (publicado, em outubro de1921, no Wiener Psychoanalytische Vereinigung). Uma análise comparativa havia sido lida por Prinzhorn em um estudo de Schilder (1918), que se afastou da pura descrição para procurar entender os processos psíquicos patológicos em analogias ao "pensamento primitivo". Desse modo, o psiquiatra e historiador da arte comparou o processo expressivo de crianças e de "povos primitivos" por meio da observação de seus desenhos ou danças, valendo-se dos resultados para pensar sobre as obras reunidas na clínica de Heidelberg.

No Brasil, o primeiro a traçar observações acerca das relações entre arte e loucura foi Ulysses Pernambucano, psiquiatra que trabalhou no Hospital Nacional e no Hospital da Tamarineira, elaborando estudos e conferências sobre o que se chamava "arte nos alienados" (Andriolo, 2004, p. 64). Motivado 
pelo Dr. Pernambucano, em 1923, o psiquiatra Sílvio Moura apresentou sua tese de conclusão de curso da Faculdade de Medicina do Rio de Janeiro, intitulada Manifestações artísticas nos alienados. É o primeiro texto conhecido no Brasil sobre o tema. Sua tese discorreu sobre as produções coletadas em alguns hospitais do país, correlacionando-as à bibliografia estrangeira. Pouco preocupado em análises aprofundadas, seu relato oscila entre referências a Lombroso e Marcel Réja, notando que tais obras despertam o interesse dos "normais" pelo que elas nos trazem de "desrazão" (Moura, 1923, p. 98).

O método comparativo estava presente nos escritos de Moura que, baseado em Reinach, aludiu que pode ser verificado o desenvolvimento da expressão plástica por meio "do estudo das crianças, que oferecem, nas sociedades civilizadas, a imagem da selvageria primitiva" (Moura, 1923, p. 104). A partir de tal observação, notar-se-ia sua evolução para a simetria, a justaposição, a cor e a composição. ${ }^{8}$

\section{Um modelo comparativo para os intelectuais brasileiros}

Um encontro significativo entre a crítica de arte e a Psiquiatria teve lugar no Hospital de Juquery, próximo a São Paulo. Seu primeiro diretor, Franco da Rocha, havia contribuído para tornar a instituição um centro de estudos psiquiátricos e também psicanalíticos, onde o jovem médico Osório Cesar desenvolveu um modelo comparativo que serviu de base para muitos estudiosos da Psicologia da Arte no Brasil.

Nascido em João Pessoa, na Paraíba (1895), Osório Thaumaturgo Cesar morreria em Franco da Rocha, em São Paulo (1979). Desde 1923, o médico trabalhou no Hospital de Juquery, onde permaneceu até a aposentadoria, em 1965. Suas idéias foram registradas em diversos escritos, entre livros e artigos de jornais paulistanos, por meio dos quais se pode acompanhar o desenvolvimento e difusão de seu método de interpretação das obras de arte (Andriolo, 2003).

8 Munido de material coletado junto a crianças cariocas e pernambucanas, Moura pôde contestar a tese do próprio Reinach, para quem a evolução dos motivos nos desenhos infantis passaria primeiro por figuras de animais, para depois realizar homens e vegetais. Revendo, também, o modelo de Réja, o psiquiatra brasileiro apresenta como primeira fase do desenho infantil a realização de flores, bandeiras e sóis (Moura, 1923, p. 108). 
Dedicou-se à Psicanálise desde 1925, quando publicou seu primeiro estudo sobre a produção de internos daquele hospital. As idéias então apresentadas de modo sintético dominaram suas explicações, tanto das obras dos internos do hospital como as de artistas do meio artístico oficial. No ano de 1929, veio a público sua principal obra, a Expressão artística dos alienados (contribuição ao estudo dos symbolos na arte), publicada pelas Oficinas Gráficas do Hospital Juquery. Essa monografia consumiu seis anos de pesquisas no hospital, tendo ocupado o jovem médico, desde 1923: "já tínhamos em mente a idéia de estudar a arte nos alienados, comparando-a com a dos primitivos e a das crianças" (Cesar, 1929, p. xxii). Tal idéia ocorrera-lhe após a leitura de Prinzhorn (1922) e Vinchon (1924), num momento em que se começava a coletar obras de pacientes naquele hospital, algumas das quais pelo seu primeiro diretor, Dr. Franco da Rocha.

A primeira parte do livro foi dedicada à construção de seu método comparativo e analítico. Trata da "loucura e arte dos loucos" e, realizando um breve resumo das análises médicas da arte nos alienados, apresenta seu quadro de classificação das obras e o valor dos símbolos nas manifestações artísticas e sua interpretação psicanalítica. Na segunda parte (a partir do capítulo 3), realiza correspondências entre algumas doenças mentais e o que seriam suas manifestações artísticas mais características.

Embora de modo indireto, como se observou, seu modelo classificatório e método comparativo têm relação com o livro de Prinzhorn (1922), ambos citados por Volmat (1955) em sua breve história das idéias de arte e loucura. Conforme Cesar (1929):

Somos inimigos das classificações. Achamos que todas elas pecam pela base e que o seu valor é apenas de ocasião, didático. Apesar disso, tivemos imperiosa necessidade de assim proceder, em vista do estudo comparativo que propomos tentar entre a arte dos alienados, do homem primitivo, a arte primitiva e a de vanguarda. (p. 160)

Por exemplo, para se ter uma idéia do funcionamento desse modelo classificatório, comparava-se a confecção de bonecas de trapos velhos e papel, na seção feminina do hospital, com o gosto dos índios Karajás por bonecas que haviam sido encontradas na Ilha do Bananal, em outubro de 1927 (Cesar, 1929, p. 48). A música praticada entre os "primitivos", a exemplo de Botocudos e Parecis, também era considerada, por ser muito comum entre os alienados (p. 51). 
O chamado "Quadro da Classificação das Artes nos Alienados (Estudo Comparativo)" resume-se no seguinte (Cesar, 1929, p. 6): $1^{\circ}$ Grupo - arte do primitivo (desenho e música); $2^{\circ}$ Grupo - arte primitiva ou arcaica (desenho, escultura, decoração, poesia, música, dança); $3^{\circ}$ Grupo - arte clássica ou acadêmica (desenho, pintura, escultura, decoração, poesia, música, dança); $4^{\circ}$ Grupo - arte de vanguarda (desenho, pintura, escultura, decoração, poesia, música, dança).

Cada grupo do quadro corresponderia a um "estilo". As obras dos internos eram comparadas com esses "estilos" e então classificadas. A comparação, porém, não era rígida, podendo uma mesma obra, em alguns casos, ser classificada em "estilos" diferentes.

O primeiro grupo era constituído pela "arte do primitivo", semelhante à dos "imbecis" e crianças de 4 a 6 anos. Para Cesar (1929), "a imaginação da criança, como a do primitivo, é realista em extremo. Os seus desenhos se limitam em arremedar a natureza com representações de cenas da vida diária" (p. 8). O indivíduo acometido pela "demência precoce catatônica" perderia a inteligência adquirida, restando-lhe apenas a "do primitivo", instintiva e filogeneticamente transmitida, daí sua correspondência com crianças e homens das cavernas (p. 161).

O segundo grupo, a "arte primitiva", distinguir-se-ia da categoria anterior, pois, no homem primitivo, ela seria representada por desenhos toscos, incompletos e caricaturais de animais selvagens, não havendo decorações de motivos vegetais: "Ela é antes uma pré-arte". A "arte primitiva", ao contrário, seria "uma manifestação estética emocional, grosseira, deformada e estilizada, com motivos animais e vegetais". Das quais são exemplos a arte do século XII, de Bizâncio, a gótica, a japonesa, a dos africanos e a dos futuristas (Cesar, 1929, p. 161). Nesse caso, as produções dos "dementes precoces paranoides", para o médico, assemelhar-se-iam muito com a "arte primitiva", seja na escultura africana, seja bizantina ou gótica.

A "arte clássica" ou "acadêmica", formadora do terceiro grupo, contempla o aparecimento da pintura, acrescido às outras manifestações. Muitas vezes, na obra pictórica, considera o psiquiatra do Juquery,

a arte dos alienados é uma arte normal, bem equilibrada e por isto mesmo sem grande interesse para o nosso estudo a não ser no tocante a um ou outro ponto 
de concepção original que ela possa ter. Por isso, comparamos as manifestações artísticas dos alienados que pertencem a esse grupo, com a arte comum, a arte acadêmica. (Cesar, 1929, p. 24)

Por fim, o quarto grupo era composto pela "arte nos vanguardistas", um tema que havia sido enunciado em 1925, quando escrevera: "A estética futurista apresenta vários pontos de contato com a dos manicômios. Não desejamos com isso censurar essa nova manifestação de arte; longe disso. Achamo-la até muito interessante assim como a estética dos alienados." (Cesar, 1925, p. 117). Em 1929, escreveu que os maneirismos estereotipados, confusos, quase indecifráveis, constituintes deste grupo, são interessantes aos olhos da Psicanálise, afirmando mesmo que a arte futurista é uma arte esquizofrênica, embora os futuristas não sejam alienados (Cesar, 1929, p. 74).

Quatro anos depois, quando convidado pelo artista Flávio de Carvalho para participar da exposição no Clube dos Artistas Modernos, a chamada "Semana dos loucos e das crianças" (1933), Cesar proferiu uma palestra intitulada "Estudo comparativo entre a arte de vanguarda e a arte dos alienados". Para sua realização, seguiu as informações do texto de 1929 e as sintetizou, posteriormente, num opúsculo levado a público em 1934, intitulado $A$ arte nos loucos e vanguardistas.

\section{Conclusão: os riscos do método comparativo}

A passagem, na aplicação do método comparativo, dos estudos de psicologia das obras de pacientes de hospitais psiquiátricos para grupos de artistas evidenciou um risco implícito em sua concepção, embora ocultado pela competência do discurso da Psicopatologia.

A relação de artistas com o outro da cultura européia ocorreu desde o final do século XIX, seja com Gauguin, que, evadido de Paris, descobriu as obras populares da Bretanha e as da Oceania, seja com Picasso, trazendo para suas pinturas referências de esculturas africanas, ou ainda, com Max Ernst, ao freqüentar a clínica psiquiátrica de Bonn. Lasar Segall, além de visitar o sanatório de Dresden, veio instalar-se no distante Brasil (Andriolo, 2004). Naquele momento, os artistas criavam para si mesmos a imagem do outsider, tendo 
como necessidade definir a vanguarda como antítese da ordem estabelecida: "O esquizofrênico tornava-se mais um artifício para os artistas que já se serviam do exotismo das culturas primitivas para a formulação de uma crítica da sociedade" (Frayze-Pereira, 1995, p. 113).

Como afirmávamos, o processo de formação das idéias em torno da obra dos pacientes de hospitais psiquiátricos, de povos aborígines, entre outros, corresponde historicamente ao processo imperialista europeu e, como tal, deve ser compreendido. Tal fenômeno movimentou-se no ritmo do colonialismo cuja primeira fase fora o "etnocídio", seguido da colonização propriamente dita, para uma integração sob novo significado. Nas palavras de Michel ThéVoz (1990): "no que concerne às produções simbólicas dos povos colonizados, passou-se da destruição à pilhagem, ou seja, para uma fase de acumulação.... Depois exploraram-nos como uma fonte bruta de inspiração própria a regenerar a arte civilizada" (p. 102). ${ }^{9}$

Nesse contexto, indagamos: qual a utilidade histórica do método comparativo na Psicologia da Arte quando focalizou o outro (externo ou interno) da civilização ocidental? Da maneira como foi praticado, tal método não teria sido um instrumento da cultura européia e ocidental de igualar os povos e grupos sociais diferentes, em oposição à sua auto-imagem? Ou, ainda, de submeter a um mesmo estereótipo negativo grupos sociais e étnicos distintos?

O Dr. Osório Cesar frequientou o campo modernista de São Paulo, escrevendo artigos e catálogos de exposições, sustentando a afirmação de que os vanguardistas não eram alienados. No entanto, sua proposição comparativa assinalava seus riscos, ao alinhar pessoas tão distintas como os habitantes da África e os pacientes do Hospital de Juquery, construindo, a partir daí, seu modelo de paralelos sintomatológicos. No campo artístico, esse procedimento permitiu a Monteiro Lobato (1951) realizar sua famosa crítica às pinturas de Anita Malfatti, em 1917, quando as comparou com os rabiscos encontrados nas paredes dos asilos. Nesse sentido, pode-se encontrar o método comparativo servindo para o julgamento negativo de artistas e loucos, como fora entre estes e os povos considerados "primitivos".

9 "pour ce qui concerne les productions symboliques des peuples colonisés, on a passé de la destruction au pillage, c'est-à-dire à une phase cumularde.... Puis on les a exploités comme une source brute d'inspiration propre à régénérer l'art civilisé". 
O médico pernambucano Gonçalves Fernandes, ao propor a comparação do surrealismo com idéias psicopatológicas, encontrou nas telas de Cícero Dias um registro de doença: "A infantilidade de uma tela de Cícero ninguém pode negar. Que ele é sincero na sua arte nós sabemos. Sabemos, também, que é um esquizóide" (Fernandes, 1933, p. 143). A comparação que dispunha as obras surrealistas ao lado das produções asilares permitiria ao médico revelar: "os complexos mascarados nos símbolos, no colorido rico de vermelho, azul e verde, sentimos ainda mais se intricarem os pontos de contato, e não mais podemos distinguir surrealistas e esquizofrênicos alienados" (p. 145).

A possibilidade de julgamento inerente ao método comparativo mostrou sua contradição mais aguda no interior do próprio continente europeu, quando Hitler incluiu em seu programa manifestações públicas que expusessem sua concepção de arte ideal. A exposição ocorrida em Munique (1937), por iniciativa de Goebbels, ministro da propaganda do III Reich, reuniu coleções de hospitais psiquiátricos com obras de artistas modernos, as quais eram comparadas por psiquiatras do Governo. Era a Entartete Kunst, ou a exposição de "arte degenerada", sobre a qual o filme Arquitetura da Destruição, dirigido por Peter Cohen, discorreu com sucesso. Artistas profissionais como Otto Dix, Heckel, Kandinsky, Kirchner, Klee, Kokoshka, Franz Marc, Nolde, entre outros, foram expostos ao lado de obras recolhidas nas coleções psiquiátricas, como aquela formada por Prinzhorn, onde figuravam peças de Karl Brendel, Paul Goesch e Georg Birnbacher.

Brendel foi o primeiro caso reverenciado por Prinzhorn, em seu livro de 1922. No catálogo da exposição de 1937, duas obras suas foram reproduzidas ao lado de esculturas modernas. Segundo Weber (1984), a legenda assim as apresentava: "Esta cabeça de moça é obra de um louco incurável da clínica psiquiátrica de Heidelberg. É compreensível que loucos não-artistas criem tais obras"10 (p. 30). Na comparação projetada pelos nazistas, a semelhança destas com as dos artistas profissionais era, pois, sinal de degeneração destes últimos, cuja comprovação era experimentalmente possível pela teoria da degenerescência e pelo método comparativo.

10 'Cette tête de petite fille est l' ouvrage d' un fou incurable de la clinique psychiatrique de Heidelberg. Il est compréhensible que des fous non-artistes créent de telles oeuvres". 
O choque provocado por essa exposição, em todos os sentidos, dos estéticos aos humanos, promoveu no pós-guerra um movimento crítico não apenas às matrizes teóricas que associaram a "arte de loucos", "primitivos", "artistas modernos" etc., mas ao uso de comparações psicológicas dessa natureza nas explicações artísticas. Neste momento, cabe indagarmos: o modo como o método comparativo inscreveu-se na origem da Psicologia da Arte não teria conferido uma validade tácita a esses julgamentos psicológicos e estéticos, vulgarizado na percepção cotidiana de muitos espectadores de arte?

Andriolo, A. (2006). The comparative method in the origin of the psychology of art. Psicologia USP, 17(2), 43-57.

\begin{abstract}
The objective of this text is to present the appearance of the comparative method in the European and Brazilian psychological interpretations of the artistic productions. It utilizes the psychiatric discourse at the beginning of the XXth century, noticing how the basic interpretations concerning the psychology of art were permeated by the comparative method. The last one presented the analytic risk of finding in art a manifestation of degeneration.
\end{abstract}

Index terms: Art (Psychology). Alterity. Degenerate art.

Andriolo, A. (2006). La méthode comparatif dans la psychologie de l'art. Psicologia USP, 17(2), 43-57.

Résumé: L'objectif de ce texte est présenter l'événement de la méthode comparatif dans des interprétations psychologiques des productions artistiques à l' Europe et au Brésil. On utilise les discours psychiatrique du début du XXe siècle, en remarquant comme les interprétations fondamentales de la psychologie de l'art ont été traversées par la méthode comparatif. Celui ci a porté le risque de trouver dans l'art une manifestation de dégénération.

Mots-clés: Art (Psychologie). Altérité. L’Art dégénéré. 


\section{Referências}

Andriolo, A. (2003). A psicologia da arte no olhar de Osório Cesar: leituras e escritos. Psicologia Ciência e Profissão, 23(4), 74-81.

Andriolo, A. (2004). Traços primitivos: histórias do outro lado da arte no século XX. Tese de Doutorado, Instituto de Psicologia da Universidade de São Paulo, São Paulo.

Cesar, O. (1925). A arte primitiva nos alienados. Manifestação esculptórica com caráter symbólico feiticista num caso de syndromo paranóide. Memórias do Hospital de Juqueri, 2(2), 111-125.

Cesar, O. (1929). Expressão artística dos alienados (contribuição ao estudo dos symbolos na arte). São Paulo: Oficinas Gráficas do Hospital Juquery.

Cesar, O. (1954-1955). A expressão artística nos alienados. Boletim de Psicologia, 6(21/24), 125-137.

Fernandes, G. (1933). Surrealismo e esquizofrenia (Contribuição sucinta ao estudo da arte na psiquiatria). Arquivos de Assistência a Psicopatas de Pernambuco, 3(2), 140-150.

Frayze-Pereira, J. A. (1994). A alteridade da arte: estética e psicologia. Psicologia USP, 5(1/2), 35-60.

Frayze-Pereira, J. A. (1995). Olho d'água: arte e loucura em exposição. São Paulo: Escuta.

Gilman, S. (1995). Difference and pathology: Stereotypes of sexuality, race, and madness. Ithaca, NY: Cornell University Press.

Glusberg, J. (1991). Arte y psicologia. EOS - Revista Argentina de Arte y Psicoanálisis, (1), 60-66.

Kris, E. (1968). Psicanálise da arte. São Paulo: Brasiliense.

Monteiro Lobato. (1951). Paranóia ou mistificação? (a propósito da exposição Malfati) (pp. 59-66). In Idéias de Jeca Tatu. São Paulo: Brasiliense. (Trabalho original publicado em 1917)

Moura, S. B. (1923). Manifestações artísticas nos alienados. These apresentada à Faculdade de Medicina do Rio de Janeiro. Rio de Janeiro: Off. Graph. do João Pestana.

Postel, J., \& Quétel, C. (Comp.). (1987). Historia de la psiquiatría. México: Fondo de Cultura Económica.

Prinzhorn, H. (1984). Expressions de la folie: dessins, peintures, sculptures d'asile. Paris: Gallimard. (Trabalho original publicado em 1922) 
Thévoz, M. (1990). Art brut, psychose et médiumnité (2e ed.). Paris: Éd. de la Différence.

Volmat, R. (1955). De l'évolution des idées sur "l'art et la folie". Histoire de la Médecine, 5(1), 29-49.

Weber, J.-P. (1972). La psychologie de l'art. Paris: Presses Universitaires de France.

Weber, M. (1984). Prinzhorn: l'homme, la collection, le livre. In H. Prinzhorn, Expressions de la folie: dessins, peintures, sculptures d'asile (pp. 1-40). Paris: Gallimard.

Will-Levaillant, F. (1980). L'analyse des dessins d'aliénés et de médiums en France avant le surréalisme: contribution à l'étude des sorces “de l'automatisme" dans l'esthétique du XXe siècle. Revue de l'Art, (50), 24-39.

Recebido em: 27.10.2005

Aceito em: 10.12.2005 